\title{
The Whence and Whither of Experience
}

\author{
Nick Treanor ${ }^{1}$ (D)
}

Received: 12 February 2017/ Accepted: 15 March 2018/Published online: 2 April 2018

(C) The Author(s) 2018

\begin{abstract}
Consider a toothache, or a feeling of intense pleasure, or the sensation you would have if you looked impassively at an expanse of colour. In each case, the experience can easily be thought to fill time by being present throughout a period. This way of thinking of conscious experience is natural enough, but it is in deep conflict with the view that physical processes are ultimately responsible for experience. The problem is that physical processes are related to durations in a very different way-not by being wholly present at each instant or sub-period, but by having temporal parts that are. There is a choice to be made, therefore, between preserving this common way of thinking of experience and preserving the fundamentality of processes. The first option holds fixed the view of experiences as occurring throughout time and takes this to constrain the category of entity to which they are identical, or upon which they supervene. The second option abandons this common view of experience by taking up a perspective on which we experience things in the world and their properties as existing or occurring a certain way, and mistakenly ascribe this ontological character to our experience as well. The second option is ultimately the better option, however, since only it can make sense of the facts of our experience.
\end{abstract}

\section{Introduction}

Much ordinary thinking on consciousness is infused with the idea that conscious experiences occur throughout periods of time. If you put your hand on a warm radiator, for instance, it's easy to think a feeling of heat begins and continues at least

Nick Treanor

nick.treanor@ed.ac.uk

1 The University of Edinburgh, 3 Charles Street, Edinburgh EH8 9AD, UK 
as long as your hand is on the radiator. So too, one might think, for pains: some are brief, such as the pain of a stern pinch, and some enduring, such as a toothache or a significant burn, but in both cases the experience of pain fills a period in the sense that one is in pain throughout the period in question. Or again, consider colour experiences: you open your eyes when facing a well-lit orange wall and an experience of orange begins and continues until you look away, or shut your eyes, or the light goes off, etc. To feel heat, be in pain, or see orange for five seconds is, on this picture, to be feeling heat, sensing pain or seeing orange throughout a five second period. Moreover, on this picture what is true of experiences of warmth, pain and colour is true of experience generally: if we experience a phenomenal quality, that phenomenal quality seems to be experienced throughout some period.

If this way of thinking of experience is correct, I will argue, then conscious experiences are not instantiated the way physical processes are, for processes are instantiated over time. This is an ontic difference, and it would rule out the possibility of psychophysical identities between experiences and processes. The upshot is that we can either (i) preserve this common way of thinking of experience and take the arguments to provide constructive constraints on the ontological kinds to which the physical entities that stand in psychophysical identity relations belong, or (ii) preserve the fundamentality of physical processes to conscious experience by reworking our understanding of experience. In the end the second option will prove the better one.

The view of experience I will defend is similar to the view of those who think that experience is transparent: experience reveals the way the world out there is, rather than anything about the intrinsic properties of experience itself. What we learn when we hold our hand on a radiator, on this alternative picture, is that the radiator is warm throughout some period; whether we experience warmth throughout this period is an open question. We might learn that the radiator is warm throughout some period by experiencing, throughout that period, its warmth. But we equally might not, for all our experience tells us. So too for being in pain, seeing orange, and so on. The duration or period in question, on this contrasting picture, is part of what was experienced, not a feature of the experiencing itself. My own view is that experience is transparent and that this alternative picture is correct. But I also think that claiming that experience is transparent at the outset, as if introspection reveals this, has no dialectical leverage: you can't tell whether experience is transparent just by looking. ${ }^{1}$ This paper therefore tries a different tack. I will claim that experience is transparent, but this will come at the end rather than the beginning of argument.

Many of the issues I explore will be familiar to philosophers who focus on our perception of time and movement and some of the issues, especially toward the end of the paper, have been treated by those philosophers in detail. ${ }^{2}$ My aim is not to speak to them, however, but to a different continent of philosophers, those who continue to operate with what I have called an ordinary or common view of how experiences occur. That view is extremely common outside philosophy of mind,

\footnotetext{
1 See Kind (2010) for an illuminating discussion of transparency.

2 See for example Dainton (2000), Hoerl (2009, 2013), Kelly (2005), Le Poidevin (2007), Phillips (2008, 2014).
} 
e.g., in ethics, where pain and other valenced sensations are often just assumed to occur throughout time, but it also remains common in areas of philosophy of mind that are at some distance from discussions of the perception of time, e.g., mental causation and the metaphysics of reduction.

The paper proceeds as follows. In Sect. 2, I clarify what it means to have the view that conscious experiences are instantiated throughout time, contrast this with what I call instantiation over time, and elaborate on the suggestion that it is a natural or common view that experiences are instantiated throughout time. I then argue that conscious experiences, so conceived, cannot be identical to physical processes, since processes are instantiated over time. To this point in the paper I defend only a conditional: if conscious experiences are instantiated throughout time, then they cannot be identical to processes. In Sect. 3, I explore two different ways one can respond, which differ in whether they affirm that experiences occur throughout time or that physical processes are fundamental to experience. The first approach takes a certain phenomenological picture as basic and insists the proper object of scientific inquiry is conscious experience so conceived. The second approach preserves the importance of processes by adopting a perspective on which the ontological character commonly ascribed to experience is instead only the character ascribed by experience to what it is an experience of. Section 4 argues that there is independent reason to prefer the second option.

\section{Conscious Experience and Physical Processes}

\subsection{A Distinction}

Consider two different ways an entity can be. First, such things (in the broadest sense) as a person, a chair, and the person's being seated in the chair: at least on the naïve conception of each, if a person is seated in a chair from 9am to 10am, this just means that she and the chair exist, and that she is seated in it, throughout that period, that is, at every instant and at every smaller stretch of time within that period. Compare this way in which something can be with the way a circumnavigation of the globe or running exists. If Jones leaves New York on January 1 and travels due east, arriving back in New York on December 31, then the circumnavigating is an event with a duration of one year, but the property "circumnavigates the globe" is not wholly instantiated at the briefer periods within that year. That is, it is not the case that at every period within that year there is an event that is itself a circumnavigation of the globe. We are happy to say, in the colloquial, that Jones was circumnavigating the globe throughout the year, but this just means that in the sub-periods within the year various temporal stages of the event occur, rather than that the event itself occurs at each of those periods. Similarly, if someone runs for an hour, it is not the case that at every time within that hour the property "runs" is wholly instantiated. For instance, it is not wholly instantiated at any instant within that hour, nor at any nanosecond. The reason for this is that, as Armstrong has said, "the concept of running is of necessity the concept of a process: meaning by 'process' here something whose different phases are different in nature." (Armstrong 1973, 10, italics in 
original) I do not know what exactly has to happen for it to be true that a person is running, but too much to happen at an instant or a nanosecond, that is for sure. When someone runs, what happens at an instant or a nanosecond is not running itself but rather some temporal stage or part of a running event.

Everyday English is an imperfect guide to the distinction between these two ways in which something can be, for in both cases we are inclined to say that the thing in question lasted from $t_{1}$ to $t_{2}$ or had a duration. But the distinction is clear once we attend to it. For terminological purposes, let us stipulate that the first kind of occurrence is throughout time, while the second is over time.

\subsection{A Natural View of Conscious Experience}

When the average person says that she feels heat, suffers pain, or sees orange, what she seems to have in mind is a view on which the feeling, suffering or seeing occurs in something like the way that sitting does. If someone puts her hand on a radiator and feels heat for five seconds, this just means, it is natural to think, that she feels heat throughout that period, that she starts feeling heat at $t_{1}$ and continues to feel heat until $t_{2}$, where that is some five seconds later. Similarly, when a person feels pain, the painful sensations seem to fill the temporal axis (we want the pain to stop, and shorter pains are less bad than longer pains, assuming we hold the intensity fixed). The claim in both cases is not about any conviction one might have that one's experience of heat or pain isn't gappy, that is, interrupted by ever so brief periods with different or no experience, but about the sense one naturally seems to have that qualitative character is felt or experienced throughout however long one feels or experiences it. The idea is vividly captured in Hume's famous argument that introspection reveals not a continuing self, but merely a succession of distinct appearances or impressions:

There are some philosophers who imagine we are every moment intimately conscious of what we call our SELF; that we feel its continuance in existence...[But] from what impression could this idea be derived?....If any impression gives rise to the idea of self, that impression must continue invariably the same, through the whole course of our lives, since self is supposed to exist after that manner. But there is no impression constant and invariable [through an entire life]....For my part, when I enter most intimately into what I call myself, I always stumble on some particular perception or other, of heat or cold, light or shade, love or hatred, pain or pleasure. I never can catch myself at any time without a perception, and never can observe any thing but the perception....[A person is] nothing but a bundle or collection of different perceptions which succeed each other.... [and the] mind is a kind of theatre, where several perceptions successively make their appearance; pass, repass, glide away, and mingle in an infinite variety of postures and situations. (Hume 2001, Treatise, 1.4.6.1-1.4.6.5)

On Hume's picture, when a person has conscious experience, the temporal axis is filled by experiences each of which "is a distinct existence, and is different, and distinguishable, and separable from every other perception, either contemporary or 
successive". [Treatise, 1.4.6.16] What's relevant for the current discussion is not his claims about the self, but only the general picture of experience he presents on which a person's conscious life is a temporally extended stream, each point of which is occupied by sensory impressions with some particular qualitative character.

A contemporary presentation of this picture of experience is put forward by Michael Antony, in a passage laying out what he calls "our conception of consciousness, or $\mathrm{CC}$ - a rich, largely pretheoretical, psychological structure that...is employed in much of our thought about consciousness." (Antony 2001, 263) Antony writes:

We at least sometimes conceive of qualitative elements (e.g., color qualia) as persisting through temporal intervals, however briefly.... When we do, moreover, the temporal interval is usually conceived as 'filled' by the phenomenal content.... How to unpack that is a delicate matter, but it seems to involve our conceiving of time itself as continuous, and taking phenomenal contents as realized at each instant within the interval....[It is helpful to employ a] spatial metaphor-that of a static, cylindrical marble pillar. In this image, time is represented by the spatial dimension along the length of the pillar. For the image to be helpful, the marble must contain impurities of different colors, shapes and lengths running through the stone. Such distinctions in the stone at different points along the pillar's length will be taken as corresponding to phenomenal distinctions within consciousness at different points in time....[W]e can appeal to the image of the marble pillar and imagine cutting through it at an angle perpendicular to its length, resulting in two shorter cylinders. The idea then would be to treat the colored patterns on the flat surface of one of the newly exposed ends-patterns resulting from the impurities in the stone at that point-as analogous to the states, at some temporal point $t$, of the developing phenomenal parts in the stream of consciousness. (274, italics in original)

Antony argues that this conception of consciousness is (or has been) employed by philosophers as distinct as Dretske, Lycan, Rosenthal, Tye, Chalmers, Jackson, Kripke and Nagel. We don't need to agree with him that this is the common conception of consciousness. All that matters is that it is $a$ common way of thinking of conscious experience, and one we can easily be led to if we don't think that experience is transparent.

Antony's careful explication of this picture of experience might make it seem less familiar than it is, since it analyses that picture rather than presents it in a familiar guise. Let's look therefore at two less finely wrought examples where this picture of experience is at work in recent philosophical discussion. I draw the examples from philosophy but the point is not that this picture is a philosophical theory of experience. The point is rather that it is not; it is a natural, naïve or common picture, and one that philosophers are as apt to assume as anyone. ${ }^{3}$

\footnotetext{
${ }^{3}$ I assumed this picture of experience in Treanor (2006), and only later came to see how it was mistaken.
} 
The first example is philosophical discussion of hedonism, an ethical theory. There it is standard to think of hedonic utility as a function of the intensity and duration of pleasure, and hedonic disutility as a function of the intensity and duration of pain, where 'duration' in these discussions clearly is intended in the throughout-time sense. To illustrate this let's look at Feldman's prominent 2004 discussion of hedonism (Pleasure and the Good Life, OUP). Here is how he describes what he calls 'default hedonism', a position he will take himself to refine, improve and defend throughout this book:

When a person experiences a feeling of pleasure, there is an event, or "episode", that consists in that person's feeling pleasure at that time. Each such episode lasts through a period of time, and so it has a duration. The pleasure experienced in the episode is of a certain intensity — or "strength" or "vividness". Of course, in real-life cases the intensity of pleasure in an episode will vary through time. Perhaps at the outset of the episode, the pleasure is of low intensity. Then it rises to a crescendo and subsequently fades. When the intensity reaches zero, the episode ends. In order to accommodate this fact, we will stipulate that the intensity of an episode of pleasure is the average strength of the feeling of pleasure in that episode.

....The amount of pleasure in an episode depends upon intensity and duration, with longer-lasting and more intense pleasures being said to contain more total pleasure. For purposes of exposition I will imagine that there is a standard unit of measurement for these amounts. I call one unit of pleasure a 'hedon'.

....[M]ore intense pleasures are intrinsically better than less intense ones, durations being equal. Similarly, longer-lasting pleasures are better than briefer ones, intensities being equal. In the case of comparisons between pleasures that differ in both intensity and duration, the one containing more hedons of pleasure is always the better. (26-28)

The picture Feldman here describes is one on which pleasures (and pains, as he says in passages not quoted) start, continue, then end, and have, at any point in that period, an intensity. How much total pleasure or pain is experienced is a function of how long the pleasure or pain lasted and how intense it was on average throughout this period. ${ }^{4}$

If one doubts that what Feldman has said in sketching default hedonism really shows that he thinks of pleasure and pain as occurring throughout time, consider his remarks later in the book, when he discusses some complications and matters of detail for the views he has defended. He points out that it would be a mistake for a hedonist to hold that the value of a life is simply the sum of the values of the episodes of pleasure and pain in the life, since this would involve pervasive 'double counting':

Suppose a person feels pleasure throughout a stretch of time that lasts five minutes....Since there are many ways to divide the period into smaller intervals, and many of these are temporally overlapping, there are indefinitely many intervals during which he feels pleasure. If we count each of these

\footnotetext{
4 The best known advocate of this sort of hedonic calculus involving intensity over duration, of course, is Bentham. Rawls $(1971,557)$ and Kagan $(2015,255)$ are other recent examples.
} 
intervals, we will overestimate the amount of pleasure he feels by counting overlapping pleasures as distinct. We must not allow for this sort of double counting. [173-174]

The solution he offers makes clear that he thinks any experience of pleasure or pain can be subdivided into briefer experiences of pleasure or pain that are as finegrained as time itself:

I propose to deal with this problem by making a simplifying assumption about time: I will assume that time can be "discretized". To say that time is discretized is to say that time is broken down into a sequence of tiny intervals. Each of the intervals is of very tiny duration; the collection of them is exclusive, in the sense that no two of them overlap temporally; and the collection is exhaustive, in the sense that there is no period of time that falls outside the collection. If you have all the minimal intervals, you have all the time there is. I prefer to let a basic intrinsic value state be a state of affairs about pleasure or pain experienced at one of these minimal intervals. In this somewhat artificial way I hope to avoid problems of double counting. From now on, when I speak of someone's feeling pleasure "at a time", I intend that the time in question be one of these minimal intervals. Episodes of pleasure with longer duration, then, can be taken to be nonbasic states containing large collections of basics. [174]

On this picture, when a person experiences pleasure or pain, she experiences it throughout time in the sense that her experience divides, along the temporal axis, as finely as anything can.

Hedonism is a view in ethics and appropriate as an example because ethicists could be expected, in the main, to be working with a common sense or natural picture of conscious experience, rather than one that is highly theory laden. At the risk of belabouring the point, let me include another example, this time from epistemology, of the throughout-time picture of experience at work. Again, the point is only to show that this is a natural or common way to think about experience.

Williamson's anti-luminosity argument runs as follows:

Consider a morning on which one feels freezing cold at dawn, very slowly warms up, and feels hot by noon. One changes from feeling cold to not feeling cold, and from being in a position to know that one feels cold to not being in a position to know that one feels cold. If the condition that one feels cold is luminous, these changes are exactly simultaneous. Suppose that one's feelings of heat and cold change so slowly during this process that one is not aware of any change in them over one millisecond. Suppose also that throughout the process one thoroughly considers how cold or hot one feels. One's confidence that one feels cold gradually decreases. One's initial answers to the question 'Do you feel cold?' are firmly positive; then hesitations and qualifications creep in, until one gives neutral answers such as 'It's hard to say'; then one begins to dissent, with gradually decreasing hesitations and qualifications; one's final answers are firmly negative. (97-98) 
What Williamson is working with is a picture on which, at any moment between dawn and noon, the person feels something on the spectrum between freezing cold and hot. The change is so gradual that, from one millisecond to the next, she cannot notice a difference. This picture seems so natural and unobjectionable that Williamson seems to think it doesn't warrant discussion. He doesn't even flag his assumption, namely that experiences of the sort he is discussing occur throughout time such that feeling cold for one second involves $1000 \mathrm{~ms}-$ long feelings of cold.

\subsection{Experiences and Processes: A Problem Put Briefly}

How conscious experiences are instantiated concerns the ontology, not the epistemology, of experience. If experiences are instantiated throughout rather than over time, therefore, this fact constrains the list of possible physical candidates for psychophysical identities. After all, if $x$ is identical to $y$, then $x$ and $y$ are really one-and so there could not be an ontological difference between them, which is what would be the case if they differed in terms of how they are instantiated.

What is odd, however, is that the most plausible physical candidates for identity, physical processes, are instantiated over rather than throughout time. That is, a process is a series of causally connected events and that series occurs over some period of time. What happens in each briefer temporal stage isn't the series itself but merely a temporal part of it. To illustrate, note that not all worlds that contain the event of Jones's sailing the Indian Ocean are worlds in which Jones circumnavigates the globe. In some he starts in New York but then is lost at sea midway across the Pacific, in others the Indian Ocean is the first and last ocean he sails, and so on. So too with running: Imagine a world that endlessly repeats a millisecond long period of the actual world as it was on August 5, 2012, around 9:50 pm British Summer Time, five seconds after a starter's pistol fired in East London. In that world's counterpart of Olympic Stadium, eight figures in racing singlets endlessly displace about $10 \mathrm{~mm}$ then fall back to where they started, 50 meters from where a veil of smoke hangs motionless for eternity in front of a stone-faced and infinitely patient crowd. This world instantiates, again and again, an event that is a temporal part of running. But in that world no one runs, there or anywhere else.

\subsection{Experiences and Processes: A Problem in Detail}

What we have, then, is an apparent conflict between a common way of thinking of experience and a very plausible story about what such experiences are. A more perspicacious presentation of the argument will make explicit what exactly the inconsistency is and what it shows.

The argument will focus on what I will call atomic conscious experiences. The term 'an experience' is an undisciplined sortal and on one way of using the term, many experiences do occur over time and decidedly not throughout. For example, consider the visual experience you would have if you watched a screen that changed colour every few seconds. We can speak of that as one experience, as indeed I just did, rather than as experiences first of blue, then of red, then of green, then of purple, and so on. That experience does not occur throughout time, on anybody's way of 
thinking about experience. For the purposes of looking at the argument more closely, therefore, we should distinguish between temporally variegated and temporally uniform experiences. As C.D. Broad put the distinction, a conscious experience "may be qualitatively variegated or qualitatively uniform throughout its duration, just as a line may vary in colour from one end to the other or be uniformly coloured throughout." [Broad 1938: 266] I will refer to qualitatively uniform experiences as atomic conscious experiences, to reflect the fact that a conscious experience that varies in terms of qualitative character is made up of conscious experiences that do not vary in terms of qualitative character, just as a thread that varies in color over its length has, within that length, some segments that do not vary in color, and varies in color over its length precisely in virtue of having such segments within it.

I should remind the reader that the remarks immediately preceding are meant to characterize a certain picture of experience, one that is at least reasonably pervasive, rather than to set out a view that I agree with. The goal of the current section is to argue for a conditional (if experiences occur throughout time, then they cannot be identical to processes), and it's helpful to be able to run the argument in the voice of someone who believes the antecedent. So although I said, in the paragraph immediately above, that a temporally variegated experience is a concatenation of temporally uniform experiences (what I've called atomic experience), this is not a view I myself hold. For instance, if you see a train rolling along a track, I take it that you perceive the train's moving, not merely that the train is at this instant here and at that instant there. But if that is right, then your experience of the moving, despite being qualitatively variegated, is something other than your having a succession of distinct atomic experiences (the variegation is part of the content, not a feature of the vehicle). Those attracted to the throughout-time picture of experiences are not likely to agree with my reading of the phenomenology, however: Insofar as that picture of experiences includes a view on the experience of motion, it takes it to be a concatenation of distinct atomic experiences. We can see this if we look more closely at the picture of experience Broad articulated, which distinguished between experiences that vary qualitatively over time and those that don't. In a longer passage, he writes:

There is evidently a very close analogy between a person's mental history, taken as a whole, and a cord made up of shorter strands arranged in the following way. The shorter strands are all parallel to each other and to the axis of the cord. No strand stretches the whole length of the cord; the strands are of various lengths and the two ends of any one strand are in general at different positions, respectively, from the two ends of any other strand. Any short segment of the cord will contain segments of several overlapping strands; but two short segments of the cord at some distance apart may be composed of wholly different strands. Some strands may be practically uniform in colour and texture throughout their length. Others may vary greatly in colour or texture from one end to the other. The former correspond to monotonous experiences, and the latter to variegated and exciting experiences. [267-268] ${ }^{5}$

\footnotetext{
5 Although the quotation nicely captures the standard picture, Broad had a more complicated view. See Broad (1923, 1938).
} 
$\mathrm{He}$ is here articulating a view on which all experience (a person's conscious mental history, as a whole) can be understood by appeal to atomic conscious experiences, just as a long and variegated rope is made up of shorter, overlapping strands of cord, each of which has some specific colour and texture at any linear point. At this juncture, we don't need to decide whether qualitatively variegated experiences are concatenations of atomic experiences or not; that would be premature. The important point is just that the picture of experience on which experience occurs throughout time takes there to be atomic conscious experiences, and for the point of running the argument, we'll assume this to be the case as well.

With this refinement in place, we can run the argument more perspicaciously. We will assume that experiences are instantiated throughout time, and that there are atomic conscious experiences, to show that such experiences could not be identical to physical processes. Let $\mathrm{W} 1$ be a world in which a subject $\mathrm{S}$ experiences orange (O) throughout a $\mathrm{t}_{1}$ to $\mathrm{t}_{2}$ period, and let $\mathrm{P}$ be the physical process to which it is alleged the experience of orange is identical. Suppose $\mathrm{P}$ is identical to the series of events $E_{1}, E_{2}, E_{3}, E_{4}, E_{5}$, where each event is of a different type (here as before I am thinking of events as property instantiations). We can diagram the relevant portion of $\mathrm{W} 1$ as follows:

\section{W1}

\begin{tabular}{|c|c|c|c|c|}
\hline $\mathrm{O}$ & $\mathrm{O}$ & $\mathrm{O}$ & $\mathrm{O}$ & $\mathrm{O}$ \\
\hline $\mathrm{E}_{1}$ & $\mathrm{E}_{2}$ & $\mathrm{E}_{3}$ & $\mathrm{E}_{4}$ & $\mathrm{E}_{5}$ \\
\hline
\end{tabular}

The diagram may make it seem as if $\mathrm{S}$ has five $\mathrm{O}$ experiences, but this is merely because it is hard to map a continuous experience using discrete letters. The diagram would be most perspicacious if the O-bar were a strip of orange. Compare this world with $\mathrm{W} 1 *$, a very short lived world. $\mathrm{W} 1 *$ is identical to $\mathrm{W} 1$ from $\mathrm{t}_{1}$ to $\mathrm{t}_{1.2}$ :

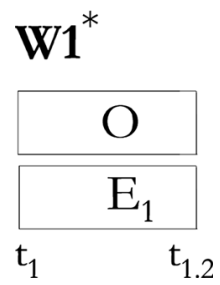

$\mathrm{W} 1 *$ is a world in which an experience of orange occurs, but in which process $\mathrm{P}$ does not occur. $\mathrm{P}$ does not occur because it is identical to the series of events $\mathrm{E}_{1} \ldots \mathrm{E}_{5}$, but in $\mathrm{W} 1 *$ only part of this series occurs, not the whole thing. Evidently, then, identity fails, for there are worlds that contain instances of orange experience but not instances of $\mathrm{P}$ processes.

The argument can be generalized to every other atomic experience and to every other physical process. All atomic experiences are like experiences of orange in that they are identified by their qualitative character. To say that they endure for T, on the picture of experience we are temporarily assuming, is to say that just that 
qualitative character is present throughout $\mathrm{T}$, or at every time within $\mathrm{T}$. But physical processes are constituted by diverse states in series, and are thus such that their temporal stages are not themselves instantiations of that very process or of a process of the same type. ${ }^{6}$

\subsection{Some Objections Considered}

The argument just given supports a conditional: if conscious experiences are instantiated throughout time, then they are not identical to physical processes. Before I discuss two distinct ways one might respond, let's consider two objections. The first insists the argument proves too much, the second that it proves too little.

That the argument proves too much: If the argument is sound, one might worry, then too much falls. For not only would we have to grant that experience is not instantiated throughout time, all sorts of properties we want to say are instantiated throughout time would fail to be. For example: it seems natural to say that a light bulb was lit throughout an hour. Nonetheless, the light bulb's being lit is identical to the flow of electrons through the filament, the excitation of atoms in the filament, and the consequent flow of electrons away from the filament. And yet all this is a process that takes place over time. Examples abound: We say someone was running throughout an hour, or building a house throughout the day, or that they shivered throughout the night. In each case, it seems natural to say that these events occurred throughout a period, even though each is surely a process. ${ }^{7}$

The problem with this objection is that it only points out that we sometimes talk of processes occurring throughout time. This is something I have already noted, however, early in the paper, when I clarified the distinction between instantiation throughout time and instantiation over time. As I put it there, we are happy to say, in the colloquial, that a ship was circumnavigating the globe throughout 2017, even though it's clear that what happens in the briefer periods within the year are temporal stages of the circumnavigation, not a circumnavigation itself. The same can be said for the examples given in the objection. We might speak of the light bulb being lit throughout an hour, but if a light bulb's being lit is really identical to

\footnotetext{
${ }^{6}$ As far as I know this argument is new to contemporary philosophy of mind. But in conversation with Noah Lemos, after this paper was substantially complete, I learned that in the course of investigating pleasure in the Nicomachean Ethics, Aristotle gives an argument that is remarkably close to the argument of the paper to this point: "[Pleasure] is a whole, and at no time can one find a pleasure whose form will be completed if the pleasure lasts longer. For this reason, too, it is not a movement....[because] in their parts and during the time they occupy, all movements are incomplete, and are different in kind from the whole movement and from each other.... it is not possible to find at any and every time a movement complete in form, but if at all, only in the whole time. So, too, in the case of walking and all other movements....the whence and whither give them their form. But of pleasure the form is complete at any and every time. This would seem to be the case, too, from the fact that it is not possible to move otherwise than in time, but it is possible to be pleased; for that which takes place in a moment is a whole." (1174a 1, 1174b 1). Alyssa Ney deserves credit for the insight that conscious experiences couldn't be identical to processes if experiences occur throughout time; she made this point to me in a working papers group when we were both $\mathrm{PhD}$ students. This paper amounts to an attempt to make the idea that experiences are or depend on processes intelligible in light of that insight.

7 Thanks to an anonymous referee, whose light bulb example and wording I use, for raising this objection.
} 
the flow of electrons through the filament, the excitation of atoms in the filament, and the consequent flow of electrons away from the filament, what happens at an instant or smallest sub-period isn't that. If there is any doubt about this, note that the description of the process is loaded with causal and diachronic terms (flow through, excitation, consequent, flow away). So too with running and shivering; running is a canonical example in philosophy and linguistic semantics of a process that occurs over rather than throughout time. ${ }^{8}$ For the argument I've given to prove too much, it has to be the case not merely that we sometimes talk of processes as occurring throughout time, some processes really do have to occur throughout time in the technical sense of that term that I introduced.

The objection as it was put doesn't show this, but could it be done? We should not be optimistic. For a property to be instantiated throughout time is for it to be wholly instantiated at every instant or smallest sub-period; for a property to be instantiated over time is to be such that all that's instantiated at an instant or smallest sub-period is a temporal stage of an instantiation of that property, not the property itself. Perhaps there is something wrong with this distinction, but on the face of it, it seems sound. ${ }^{9}$ What we would need is a reason to think this distinction itself is somehow confused or incoherent.

There is another, more subtle way of interpreting the proves-too-much objection. ${ }^{10}$ Perhaps the real force of it is not that the argument I've given runs into counterexamples, but that the abundance of cases in which 'throughout time' is used with reference to processes that unfold over time should weaken our confidence that conscious experience is commonly thought of as occurring throughout time in the technical sense. Read this way, the objection grants that experiences do occur throughout time, but just in the sense that running, shivering, and lamps-being-lit do-and it says that that is all anyone ever meant anyway.

This reading of the objection would be trenchant if I had tried to establish that it was common to conceive of experience as occurring throughout time in the technical sense by pointing to the naturalness of talk of experience that uses 'throughout'. My strategy, however, was quite different. I tried to draw out sympathy in the reader for this conception of experience by describing it in detail, and to bolster this by quotations from philosophy, drawn from different areas and ages, that showed this conception of experience at work. In the Feldman quotation, for example, he explicitly holds that experiences of pleasure and pain occur at the smallest possible interval of time, and that any longer period of pain is a concatenation of these basic states. Similarly, Antony's analogy of the marbled

\footnotetext{
${ }^{8}$ E.g., "run...has non-homogeneous minimal parts: there are parts of running events which are just too small to count as events of running." (Rothstein 2004, 11)

9 The distinction I draw between instantiation throughout time and instantiation over time, as a general distinction of ontology, is familiar and uncontroversial. The locus classicus for contemporary discussion is Vender (1957). He describes what I call instantiation throughout time this way: "A loved somebody from $t_{1}$ to $t_{2}$ ' means that at any instant between $t_{1}$ and $t_{2}$ A loved that person" (149, italics in original). What I call instantiation over time corresponds to what he describes as processes that "consist of successive phases following one another in time". (144)

10 Thanks to an anonymous referee for suggesting this.
} 
pillar makes clear that he is describing a conception of experience (which he endorses and takes to be ubiquitous) on which it is wholly instantiated at instants.

If there is lingering scepticism toward the claim that it is common or natural to think of experience as instantiated throughout time in the relevant sense, consider that if experience occurs over time, there would have to be a period of time at which one was in pain even though there was no instant or period within that period at which one felt anything. That is something that most people would find it hard to make sense of; how could you have been in pain throughout a time if you didn't feel any pain at any point within that time? Antony insists on the unintelligibility of just this idea:

According to $\mathrm{CC}$, phenomenal content is conceived as progressing continuously through time, filling at least some intervals. Which means that within such intervals experiential content is conceived as proceeding through each point in time. But then at each point there will be some way that content isthere will be facts about which contents are realized.... Attempt to see what remains of your intuitive picture of phenomenal consciousness developing through a temporal interval if you suppose that at every point in the interval there is no way your experience is phenomenologically. My picture collapses. (274, italics in original)

This quotation captures not only that it is common to think of experience in the way I've described, but that the alternative (so long as you are in the grip of this conception of experience) seems unintelligible.

That the argument proves too little: a second objection grants that if experiences occur throughout time then they could not be identical to physical processes, but worries that this leaves untouched the possibility that other relations of central metaphysical importance hold between experiences so conceived and processes. For all that has been said, the objection insists, throughout-time experiences could still supervene on physical processes, or be realized by them, or be ontologically dependent on or determined by them, or be grounded in them. The idea is that unless more is at stake than identity, the argument is of limited scope or interest.

The first thing to note in response is that this is not really an objection. Even if the argument we are discussing concerned only identity, it should interest anyone who takes the possibility of psychophysical identities seriously, as many of us do. Those who are already convinced that the identity theory is false might find little here to interest them, but it is hard to see that this in itself is an objection.

But a second and more important thing to note is that the complaint is mistaken about the force of the argument, which is directed at the identity claim but not limited to it. It would take us too far afield to consider in detail each of dependence, determination, supervenience, realization and grounding, not least because there are numerous ways to construe each of these relations. But I will offer a general picture of the reach of the argument, which shows that the throughout-time conception of experience threatens not merely the identity of conscious experience and neural processes, but any claim that takes neural processes per se to be fundamental to conscious experience. In particular, I will show that the argument demonstrates that if conscious experience is instantiated throughout time, then experience will fail to even weakly supervene on neural processes. 
The simplest way to make the point is by noting that what the argument demonstrates is that, if experience occurs throughout time, then there are worlds in which conscious experience occurs but no neural process occurs. We need only imagine a world that lasts for merely one attosecond, the time it takes light to travel the length of three hydrogen atoms, and that is a physical and phenomenological duplicate of some attosecond long period in the actual world as it was today. If conscious experience occurs throughout time, then that world will have a few billion attosecond-long conscious experiences. But that world will contain no neural processes, since nothing neural happens that fast. (This is not the claim that nothing in the brain happens that fast; quarks emit gluons more quickly than that, whether they are in the brain or not. It is rather the claim that neural processes, processes identified in the neural sciences, don't happen that fast.) This is an empirical conjecture but a safe one. If one is worried about it, just cut more finely: use a zeptosecond-long slice, which is 1000 times 'thinner', or a yoctosecond-long slice, 1000 times thinner again. The existence of worlds that contain conscious experience and no neural processes, however, is incompatible with the claim that neural processes are fundamental to experience, just as the existence of mental entities in a world without matter is incompatible with the claim that the physical is fundamental to mentality.

We can make this claim more precise by noting that the argument demonstrates that if experience occurs throughout time, then the property 'having a conscious experience' will fail to even weakly supervene on the property 'having a neural process'. This is very easy to miss, or to misunderstand. The canonical formulation of weak individual supervenience is:

A weakly supervenes on $\mathrm{B} \Leftrightarrow$ in all possible worlds $\mathrm{w}$, all individuals $\mathrm{x}$ and $\mathrm{y}$ that are B-indiscernible in $\mathrm{w}$ are A-indiscernible in w. (Leuenberger 2008)

What the argument we've considered demonstrates is that if experience occurs throughout time, then there are possible beings, even within the same world, that are indiscernible in regard to whether they have neural processes but not indiscernible in regard to whether they have conscious experiences. It might seem otherwise, since the argument leaves open that the occurrence of neural processes metaphysically necessitates the occurrence of conscious experiences. But that is not enough to satisfy even weak supervenience. ${ }^{11}$ Consider the attosecond-long world we have already considered, which duplicates an attosecond-long period in the actual world, and let us again assume for a moment that experience occurs throughout time. The short-lived counterpart of me instantiates an attosecond of conscious experience, an

\footnotetext{
11 The term 'supervenience' is sometimes used in a broader sense according to which if a certain physical property suffices for a certain mental property, then the mental property supervenes on the physical property. I follow Brian McLaughlin and Karen Bennett however in taking this to be a distinct relation from supervenience: "To see that such entailments [relations of metaphysical necessitation] do not suffice for supervenience, consider the properties being a brother and being a sibling. Possessing the former entails possessing the latter; every brother is a sibling. But being a sibling does not supervene on being $a$ brother. Two people can differ with respect to being a sibling despite being exactly alike with respect to being a brother. To see this, suppose that Sarah has a sister and Jack is an only child. Thus Sarah is a sibling and Jack is not, though neither is a brother. So the B-properties can entail the A-properties, even though A does not supervene on B." (McLaughlin and Bennett 2011)
} 
image, say, of a table, an expanse of white paper, a blue pencil. The short-lived counterpart of my blue pencil, in contrast, instantiates no experience at all. So the two are discernible in regard to whether they have conscious experience; one has it and the other does not. But the two are indiscernible in regard to whether they have neural processes; neither has any neural process at all. Hence if experience occurs throughout time, the relation between having conscious experience and having a neural process does not even satisfy weak supervenience, which corresponds to the minimum supervenience slogan of no difference in A without a difference in B.

It's important to note that the current claim isn't that if experience occurs throughout time, then any particular type of conscious experience could occur without any particular type of neural process. That would get us no more than the non-identity of types of experiences and types of processes, which has already been shown to follow from the throughout-time conception of experience. The current claim is rather that the argument we have considered shows that if experience occurs throughout time, then every type of conscious experience could occur without any neural process at all occurring. This is a much stronger claim, and one that does much more to threaten the view that neural processes are fundamental to conscious experience.

\section{Two Lines of Response}

If the throughout-time conception of experience entails that experiences are not identical to physical processes, and that a being could have conscious experience, indeed any type of conscious experience, without having any neural process at all, we seem to have two options. The first is to deny that processes are where the money's at. This option preserves the throughout-time picture of experience and takes the arguments to reveal constructive constraints on the empirical search for whatever stands on the physical side of the psychophysical relation. The second option is to abandon this common way of thinking of experience and preserve instead the centrality of processes.

The first option points to a certain picture of conscious experience and takes the proper object of scientific inquiry to be conscious experience so conceived. Proponents of this approach would be motivated by the view that science is supposed to account for the phenomena. If a bit of philosophy reveals that physical processes are not the sort of things that could be identical to conscious experience, then philosophy has helped narrow the search. Barry Dainton expresses this approach to philosophical methodology well when he writes: "If a claim about experience is both firmly grounded in the phenomenological data and in conflict with the picture of ourselves that is provided by one or another of the natural sciences, questioning the relevant science is at least as reasonable as questioning the relevant phenomenology....situations in which the phenomenological data conflict with accepted science may well provide valuable clues as to how the relevant science may be revised and improved." (22-23)

The second option goes the other way: it is not processes that should be abandoned but rather the picture of experience as instantiated throughout rather than 
over time. Some will insist that abandoning this picture is impossible, on the grounds that the alternative conception is incoherent. If experience is instantiated over time, they will point out, then it has to be possible to experience pain for a period of time without experiencing it at any point within that period. But, they will insist, that doesn't make any sense: to feel pain for five seconds requires feeling it at every point within that five seconds. This concern is exactly right-so long as one thinks of experience as occurring throughout time. But the concern dissolves if we free ourselves from that understanding, as we can.

To make the over-time conception of experience intelligible we need only construe the 'throughout time' character the naïve view ascribes to experience as, instead, something experience ascribes to what it is an experience of. The general move required is one that preserves the phenomenological fact that we experience periods of cold, warmth, orange, pain and so on, but makes intelligible that we do this without experiencing cold, warmth, orange, pain and so on at any point within those periods. More specifically, what is needed is a picture on which periods of warmth, cold, orange, pain and so on are periods that we experience, with the experience itself occurring over time, rather than periods throughout which we experience. A proponent of the naïve view takes the throughout-time character present in experience to be a feature of our experiencing itself, rather than a feature ascribed by our experience to what it is an experience of. On her view, when we put our hand on a radiator a feeling of heat begins and continues at least as long as our hand is on the radiator. On the current proposal, in contrast, it isn't that we experience, throughout time, the heat of the radiator, it is that we experience the heat of the radiator as occurring throughout time. And that we experience via a neural process that occurs over time.

There are several ways such a view could be developed and I will not attempt to set out or explore them here. However, just to give a clearer sense of the general move, consider a model on which conscious experiences are representational processes, instantiated over time, the content of which is that some qualitative property is instantiated (out there in the world) throughout some period. The representing of $\mathrm{C}$, where $\mathrm{C}$ is the content "orange, throughout period $\mathrm{T}$ ", is instantiated over some period $\mathrm{T}^{*}$ (which may or may not be identical to $\mathrm{T}$ ). This model has two aspects: it makes that the qualitative character occurs throughout time part of the content of the representation, and it posits a representational vehicle that is instantiated over time rather than throughout time. The first claim is that it is part of the representational content of an experience that a certain qualitative property is instantiated throughout some period; in situations I would normally describe as "seeing orange for $t$ ", that orange occurs throughout $t$ is part of the content of the representation. The second claim, distinct from this, is that the representing of this content, or the representational vehicle that bears this content, is something that occurs over time rather than throughout time; this is a claim about how it is that the represented properties are represented. 


\section{Saving the Phenomenology}

I will close the paper by shifting the direction of the dialectic. The main argument has been that a common way to think of experience is as occurring throughout time, that this is incompatible with the view that physical processes are fundamental to experience, and that, in response, we can either identify physical entities that are instantiated throughout time or conceive of experience such that it is instantiated over time. At this point both responses are merely schematic, indicating two distinct directions in which a solution, and all its details, might be found. I will close the paper by offering reason to look in the latter direction.

The first line of response is motivated by the anti-transparency assumption that introspection reveals that experience is instantiated throughout time, that when we put our hand on a warm radiator, for instance, we feel warmth throughout a period. If experience is so instantiated, then we have to shape our psychophysical theory around that. The problem, however, is that there is a powerful phenomenological intuition that experience is 'temporally thick', which, if transparency fails, entails that experience is not instantiated throughout time. So the advocate of the first approach is forced to have her cake and eat it too: she endorses the view that experience occurs throughout time, since, denying transparency, it seems to, but she has to grant that experience itself has a minimum temporal extent since, denying transparency, it seems to. But these claims cannot both be true: If experience is instantiated throughout time, then it has no minimum temporal extent.

I will look in a moment at the problem the temporal thickness of experience creates for a person attracted to the first line of response, and at how it presents no such problem for an advocate of the second. But first, what does it mean to say that experience is temporally thick, and what can be said in defence of the claim that it is?

The first thing to note is that it is difficult to explain the claim that experience is temporally thick in language that is neutral between, or acceptable to both, a proponent and denier of transparency. With this caveat in mind, however, let me put the point this way: Imagine the smell of a rose, or the sound of a foghorn, and then try to imagine that scent or sound being present in your olfactory or auditory field for just one billionth of a second. If you think this is impossible, then you think that experience has a minimum temporal thickness, one greater than one-billionth of a second. The opponent of transparency will take it that what is revealed is that experience itself has a minimum temporal extent, whereas the advocate of transparency will deny this, maintaining that what is revealed is that experience presents the world with a minimum temporal resolution. Notice that strictly speaking it could be misleading to say that the transparency advocate holds that experience is temporally thick, since she thinks the thickness is a matter of what is experienced rather than of the experience itself. But that expression is common enough that it's useful to stick with it.

With this caveat in place, why think that experience is temporally thick? Most people perhaps will be content not to ask for argument, insisting that there is just no way that an experience - of pain, of orange, of the scent of a rose, of the warmth of 
the sun, of the quiet and contented boredom of a lazy afternoon, and so on-could be instantaneous, or have an apparent period of merely a picosecond, for example $\left(10^{-12} \mathrm{~s}\right.$, the time it takes light to travel about $1 / 3$ of a mm). It may not be possible to improve on this, but let us try to develop an argument for the view. The strategy will be to assume that experiences are not temporally thick and then show that this, coupled with a pair of plausible metaphysical principles, entails the possibility of a situation that we cannot make sense of.

Consider by way of example an experience of a pleasant scent, or of a loud sound, or of a sharp pain, where each experience has a temporal thickness of only $10^{-12} \mathrm{~s}$. If someone claimed that I had, as I typed that last sentence, felt merely $10^{-12} \mathrm{~s}$ of sharp pain, we could not settle the question by appeal to my memory, for we would have no way of knowing whether I felt so brief a pain but did not remember it, or did not ever feel it at all. However, if such experiences are metaphysically possible then it should be metaphysically possible to have many such experiences one after the other, where each successive experience has a different qualitative character than the one preceding it. I here rely on two assumptions that most philosophers will share. The first is that the phenomenal supervenes on the intrinsic, in the sense that intrinsic duplicates at $t$ are phenomenal duplicates at $t .^{12}$ The second is the Humean dictum to the effect that there are no metaphysically necessary connections between wholly distinct entities intrinsically characterized. The idea is that if you accept that what experiences a subject has supervenes on intrinsic properties of the subject, then Hume's dictum guarantees the metaphysical possibility of any successive arrangement of such experiences.

Assume for reductio that such experiences are possible and that your auditory field is filled with the sound of a foghorn for $10^{-12} \mathrm{~s}$, followed by the sound of heart rate monitor flatlining for $10^{-12} \mathrm{~s}$, followed by the foghorn sound for $10^{-12} \mathrm{~s}$, followed by the flatlining sound again, and so on, where the apparent volume of these sounds is similar. Note that you are not asked to suppose you are listening to something that produces a different sound every $10^{-12} \mathrm{~s}$. Rather, your auditory field changes from the foghorn sound to the flatlining sound every $10^{-12} \mathrm{~s}$. In qualia talk, you have foghorn qualia, then flatlining qualia, then foghorn qualia, and so on, where each has a apparent duration of $10^{-12} \mathrm{~s}$. What would it be like to be you having such experiences? It is very difficult to say. At first glance, the answer would seem to have to be "That depends on when you ask- are you picking out a time at which I have foghorn qualia, or a time at which I have flatlining qualia?". But, on the other hand, it seems inconceivable that any auditory experience could be like that. Surely introspection would not reveal that your auditory field is changing very quickly from foghorn qualia to flatlining qualia to foghorn qualia to flatlining qualia, etc. Nor does it seem right to say that either foghorn qualia or flatlining qualia would dominate, for by hypothesis each is present for the same amount of time-if the foghorn qualia dominated, such that when you introspected your auditory field all you heard was foghorn sound, then it would seem that the thing to say is that your

\footnotetext{
12 Some representationalists about consciousness experience will not share this view, but as Alex Byrne and Michael Tye have acknowledged, many or most other philosophers think "qualia externalism...is an absurd thesis, accepted by a handful of philosophers with too much respect for philosophical theory and not enough common sense." (Byrne and Tye 2006, 242)
} 
auditory field is occupied by foghorn qualia, not that it is occupied alternatively by foghorn qualia and flatlining qualia. Nor, or course, would introspection reveal some other qualia halfway between foghorn and flatlining (an acoustic blur, so to speak), for by hypothesis your auditory field is such that it is only ever occupied by foghorn qualia or flatlining qualia; it is never occupied by any other qualia. Nor, finally, does it make much sense to suppose that you would introspect your auditory field and discover nothing-for by hypothesis your auditory field is full of qualitative character. But these exhaust the possibilities.

One might think this thought experiment reveals only an epistemic failuregiven the description of the situation, we cannot predict what it would be like. But this is to miss the point. It is not that we cannot decide between phenomenological possibilities. It is that none of the four options seems a phenomenological possibility at all given the phenomenological facts stipulated.

If this line of thinking is sound, then experience is temporally thick, with a thickness somewhat longer (a fair bit longer) than $10^{-12} \mathrm{~s}$. And this is a serious problem for an advocate of the first of the two options outlined, the one that preserves the throughout-time conception of experience. This is because that option is attractive only if one thinks transparency fails, but if transparency fails, then the minimum thickness would be that of experience itself, rather than merely the minimum temporal resolution with which experience represents the world to us. If experience is instantiated throughout time, however, as the advocate of that first option maintains, then experience couldn't have a minimum temporal extent. To have a one-second foghorn-sound quale, on this way of thinking of experience, requires having a half-second one, a quarter-of-a-second one, and eighth-of-asecond one, and so on, all the way down to $10^{-12} \mathrm{~s}$ and beyond. The problem for an advocate of the first option, in other words, is that the very thing that motivates the conviction that experience occurs throughout time, the rejection of transparency, commits her to interpreting the minimum thickness intuition as revealing a fact about experience itself, one that is inconsistent with the claim that it occurs throughout time. An advocate of the second line of response, in contrast, has no trouble accommodating the temporal thickness of experience. On her view it is a matter of what is experienced rather than of the experience itself, and the fact that one experiences that a foghorn sound is present throughout some one second period does not entail that one experiences, or can experience, that a foghorn sound is present throughout some $10^{-12}$ s period. Experience just doesn't represent the world at that fine a resolution.

Open Access This article is distributed under the terms of the Creative Commons Attribution 4.0 International License (http://creativecommons.org/licenses/by/4.0/), which permits unrestricted use, distribution, and reproduction in any medium, provided you give appropriate credit to the original author(s) and the source, provide a link to the Creative Commons license, and indicate if changes were made.

\section{References}

Antony, M. (2001). Conceiving simple experiences. The Journal of Mind and Behavior, 22(3), $263-286$. Aristotle, Nicomachean Ethics 
Armstrong, D. M. (1973). Belief, truth and knowledge. London: Cambridge University Press.

Broad, C. D. (1923). Scientific thought. London: Kegan Paul, Trench and Trubner.

Broad, C. D. (1938). Examination of McTaggart's philosophy (Vol. II). Cambridge: Cambridge University Press.

Byrne, A., \& Tye, M. (2006). Qualia ain't in the head. Noûs, 40(2), 241-255.

Dainton, B. (2000). Stream of consciousness: Unity and continuity in conscious experience. New York: Routledge.

Hoerl, C. (2009). Time and tense in perceptual experience. Philosophers' Imprint, 9(12), 1-19.

Hoerl, C. (2013). A succession of feelings, in and of itself, is not a feeling of succession. Mind, 122(486), 373-417.

Hume, D. (2001). A treatise of human nature. In D. F. Norton \& M. J. Norton (Eds.), Oxford: Oxford University Press.

Kagan, S. (2015). Introduction to ill-being. In M. Timmons (Ed.) Oxford studies in normative ethics, Vol. 4. Oxford: Oxford University Press

Kelly, S. (2005). The puzzle of temporal experience. In A. Brook \& K. Akins (Eds.), Cognition and the brain: The philosophy and neuroscience movement (pp. 208-238). Cambridge: Cambridge University Press.

Kind, A. (2010). Transparency and representationalist theories of consciousness. Philosophy Compass, 5(10), 902-913.

Le Poidevin, R. (2007). The images of time: An essay on temporal representation. Oxford: Oxford University Press.

Leuenberger, S. (2008). Supervenience in metaphysics. Philosophy Compass, 3, 749-762.

McLaughlin, B., \& Bennett, K. (2011). Supervenience. In E. N. Zalta (Ed.), The Stanford encyclopedia of philosophy (Winter 2011 Edition)

Phillips, I. (2008). Perceiving temporal properties. European Journal of Philosophy, 18(2), 176-202.

Phillips, I. (2014). The temporal structure of experience. In D. Lloyd \& V. Arstila (Eds.), Subjective time: The philosophy, psychology, and neuroscience of temporality. Cambridge: MIT Press.

Rawls, J. (1971). A Theory of Justice. Cambridge: Harvard University Press.

Rothstein, S. (2004). Structuring events: A study in the semantics of aspect. Oxford: Blackwell.

Treanor, N. (2006). The cogito and the metaphysics of mind. Philosophical Studies, 130(2), 247-271.

Vendler, Z. (1957). Verbs and times. The Philosophical Review, 66(2), 143-160. 